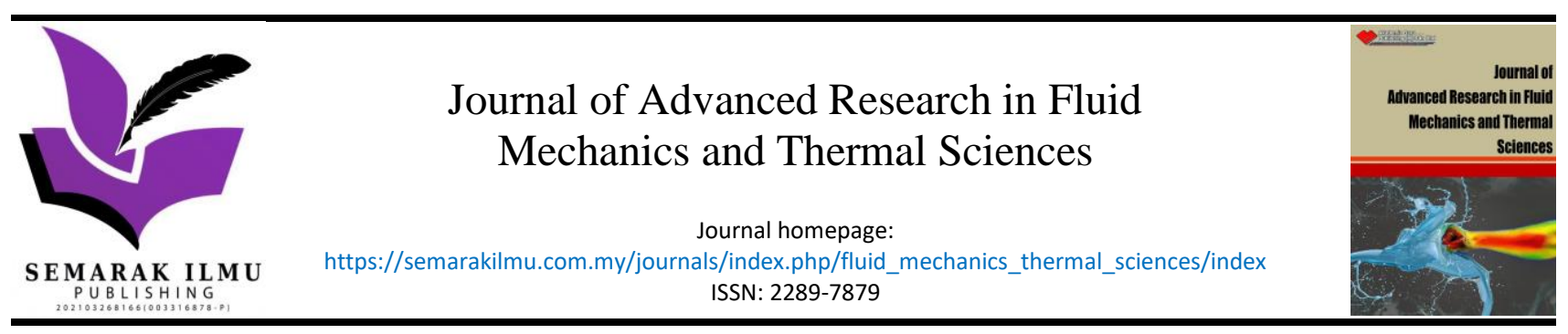

\title{
A Review of Aerodynamics Influence on Various Car Model Geometry through CFD Techniques
}

\author{
Muhammad Nabil Farhan Kamal1, ${ }^{1,}$, Izuan Amin Ishak ${ }^{1,2, *}$, Nofrizalidris Darlis ${ }^{1}$, Daniel Syafiq Baharol \\ Maji $^{1}$, Safra Liyana Sukiman ${ }^{3}$, Razlin Abd Rashid ${ }^{1}$, Muhamad Asri Azizul ${ }^{1}$ \\ Department of Mechanical Engineering Technology, Faculty of Engineering Technology, University Tun Hussein Onn Malaysia, Edu Hub Pagoh, \\ 84600, Muar, Johor, Malaysia \\ 2 Sustainable Engineering Technology Research Centre, Universiti Tun Hussein Onn Malaysia, Edu Hub Pagoh, 84600, Muar, Malaysia \\ 3 Centre for Language Studies, University Tun Hussein Onn Malaysia, Batu Pahat, Malaysia
}

\section{ARTICLE INFO}

Article history:

Received 27 July 2021

Received in revised form 28 August 2021

Accepted 5 September 2021

Available online 18 October 2021

\section{Keywords:}

Aerodynamic Forces; Car; CFD; Car

Model; Design; Flow separation; Safety

\section{ABSTRACT}

The aerodynamic characteristics of a vehicle play a vital role in steering stability, performance, comfort, and safety of a car. The fuel efficiency of a vehicle is determined by the performance of the internal combustion engine and the aerodynamic design of the body. One of the most important aspects of automobile design is aerodynamic styling. A vehicle with low drag resistance provides advantages in terms of cost and efficiency. This article will review design characteristics and implementation of various specific reference models on drag issues using Computational Fluid Dynamics (CFD) techniques. The benefits and limitations of these models are analysed, and the validity of results in developing guidelines to improve the performance and stability of cars are described. This review paper covers significant studies that utilise the CFD model and simulation on a simplified vehicle model using various turbulence models to generate drag coefficient. Characteristics and impacts of various vehicle design models with and without external factors such as side mirrors and door handles are also discussed. Results obtained from the research focuses on the physics flow structures such as static pressure contours, are presented for the three types of car model geometry. The simplified generic models are more efficient and advocated to apply compared to the specific model geometry based on the result acquired by the latest studies. Simplified generic models are preferred due to their cost-effectiveness, procurement of optimum time, and better simulation effects. Moreover, the study also demonstrates the importance of having a car with suitable turbulence models that are appropriate to be applied for simulations in terms of its applicability, time effectiveness, and cost.

\section{Introduction}

Recent development area of high-speed cars aims to minimize aerodynamic force for safety improvement, parallel with the growth of highways and roads. Innovations in automotive technology

\footnotetext{
* Corresponding author.

E-mail address: nabilfarhan1910@gmail.com

* Corresponding author.

E-mail address: izuan@uthm.edu.my
}

https://doi.org/10.37934/arfmts.88.1.109125 
illustrate a tendency in producing faster, more powerful, and lighter cars. One of the significant criteria in designing a modern car is an acknowledgement of general safety, namely stability and control over the car [1-4].

'Aerodynamics' is defined as the study of airflow, especially when it interacts with moving objects [5-7]. It can be divided into two categories, namely (a) External Aerodynamics, which interacts with the flow of a solid body in various shapes and (b) Internal Aerodynamics, which concerns the flow that passes through the internal compartment of a solid body based on the study by Desai and Molvi [8]. Aerodynamic drag is another essential factor that affects the stability, energy efficiency, and performance of cars $[9,10]$.

The velocity and design of an automotive vehicle have a significant impact on aerodynamics. Hence, it is important to reduce the air resistance and lift coefficient of a vehicle to increase its performance. In the terms of aerodynamics, among the main forces that need to be inspected are lift, thrust, drag, and weight $[11,12]$. The theory of forces derived from air movement around a vehicle can be categorized into two parts, namely (a) Downward Force (lift force) and Aerodynamic Drag (air resistance). The downward force acting on the vehicle due to the difference of air pressure can enhance the performance of the car due to the force that leads to the stability of the vehicle is increased $[13,14]$. On the other hand, the lift force is one of the net force's components that is perpendicular (or normal) to the flow direction. As shown in Figure 1, this net force component along the flow of direction is called drag force [15]. It is defined as a force that opposes motion due to the shape, material, and speed of an object $[12,16]$. It is called aerodynamic drag force if the fluid is air and drag force has the greatest attention as compared to other forces due to its significant impact on fuel consumption [17-21].

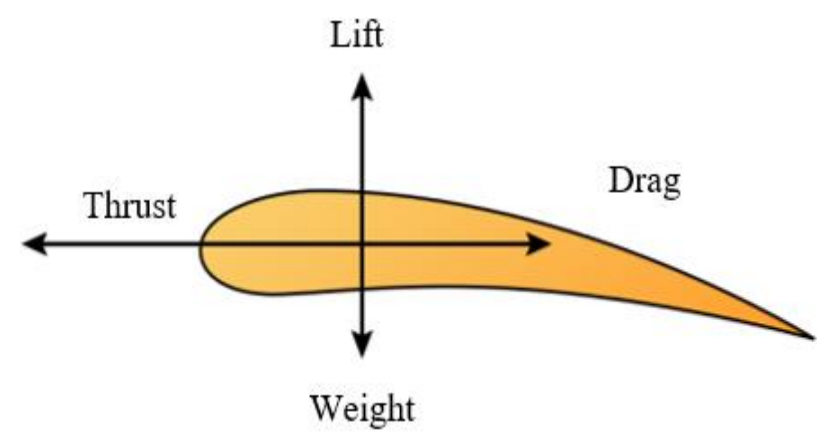

Fig. 1. Element of the net forces for vehicle [15]

Previous findings have annotated that the shape of car model geometry is important and varieties of vehicle design have been applied in both experimental and numerical studies [1,4,12,22-24]. These shapes can be classified into three categories namely simple bodies, basic car shapes, and production (series) cars [24]. These simple bodies can be described as simplified and generic car model with neglected external parts, utilised for general analysis and research such as in the Ahmed model, ASMO geometry, and Davis model. Next, the basic car shapes are related to the simplified car model with some of its external parts are used for instance, side mirrors, utilised for the means of validation, correlation, and investigation such as in MIRA reference car, TATA, and SAE reference car. Whilst the production (series) cars are known as the small-scale and full-size versions with some of the external parts are applied, used for varieties of specific investigation and correlational studies such as in the actual model of Audi A4 and hybrid electric vehicle [24]. This study assesses the application and characteristics of the simple bodies, basic car shapes, and production cars as a reference model for vehicle aerodynamic performance. This review paper highlights the importance of developing a lot 
of design car models that affect simulation efficiency, avoiding vortices formation, and the overall drag force acting on the car to improve aerodynamic performance.

\section{Computational Fluid Dynamics (CFD)}

Computational Fluid Dynamics (CFD) systems are built with numerical algorithms and equations that can solve fluid flow problems especially when it comes to aerodynamics in vehicles [25]. CFD is also a mechanism to figure out the governing equations of flow [26-28]. Based on the latest study conducted by Soares [29], differential reliability and performance of turbulence models are applied in CFD software to determine the aerodynamic features of vehicle and passenger cars. As for airflow and aerodynamics simulation, three different CFD techniques are employed, Reynolds-Averaged Navier-Stokes (RANS), unsteady RANS (URANS), and Large Eddy Simulation (LES) [30-35]. The Reynolds-Averaged Navier-Stokes (RANS) solves time-averaged steady-state Navier-Stokes equations while the unsteady RANS numerically solves unsteady Navier-Stokes equation [36-38]. On the other hand, the Large Eddy Simulation (LES) solves space, position, area, and size for averaged NavierStokes equations spatially. Based on the review, the most common CFD-techniques applied is the Reynolds-Averaged Navier-Stokes (RANS) due to its low computational cost and capability in producing accurate and reliable results for simulation.

The Reynolds-Averaged Navier-Stokes (RANS) equations are time-averaged equations for fluid flow motions and mostly used to represent turbulent flows [39-41]. The characteristics of turbulence flow provide approximate time-averaged alternatives for the Navier-Stokes equations $[42,43]$. The Reynolds-Averaged Navier-Stokes non-linear equations cannot be solved numerically and mathematically. In the RANS method, instantaneous velocity and pressure are divided into fluctuating and average components.

Various turbulence models are available in the Reynolds-Averaged Navier-Stokes (RANS) approach, including Standard $k-\varepsilon$, RNG $k-\varepsilon$, Realizable $k-\varepsilon$, Spalart-Allmaras, Standard $k-$ $\omega$, SST $k-\omega$, and Smagorinsky turbulence model. The $k-\varepsilon$ is less accurate as it is near to the wall as compared to the $k-\omega$ turbulence models [44]. This is because the modelling of the $\varepsilon$ equation is neither precise nor simple to be resolved. It is important for the $k-\varepsilon$ turbulence models to use wall treatment in order to improve simulation results near the wall based on research by Al-Saadi [44].

The accuracy of drag results is on the medium performance for the $k-\varepsilon$ model as compared to other models. It is not feasible to predict the overall flow pattern around a car [29]. Any vortex in the wake area is not fully detected as there is no separation and vortex formation distinguished at both sides of the car. However, this model is very cost-effective as compared to other models in terms of computational cost, time and memory usage. Notably, the $k-\omega$ model provides the most precise results in terms of drag results. Nonetheless, wake vortex predicted is bigger and recirculation region at the wake is greater as compared to the $k-\varepsilon$ model $[29,45]$. The $k-\omega$ models outperform the $k-\varepsilon$ model in terms of overall performance although its computational cost is higher than the $k-$ $\varepsilon$ model. Most journals studied in this review paper applied the $k-\varepsilon$ model and the $k-\omega$ model due to its aerodynamic and airflow concepts. The $k-\varepsilon$ model is preferred when a study involves with free-shear layers and wake field whilst the $k-\omega$ model is suitable to provides more accurate solutions in the near wall boundary regions [46-49].

\subsection{Various Car Model Geometries}

In terms of understanding and appreciating existing design practices and operational requirements for car model geometry, it is crucial to conduct a comprehensive review of past studies. Hence, this review will focus on previous studies related to the influence of various car model 
geometries on aerodynamic forces. Annotations from various sources such as journals, thesis, and websites are analysed critically to obtain related information on three types of car model geometries. Various car model geometries can be classified into simple bodies, basic car shapes, and production (series) cars.

\subsubsection{Simple bodies}

Reference models in this classification are proven to be extremely significant in explaining the fundamental flow behaviour in vehicles synchronized with the definition of 'simple' $[24,50]$. This simple bodies can also be defined as a highly simplified model that is used for study and evaluation, with all its external parts are ignored. Ahmed model is one of the prominent models used for aerodynamic analysis that can be classified as simple bodies [51,52]. This model is more likely similar to family car ratios because it is slightly longer, bigger, and exhibits the same flow patterns. It also consists of a blunt nose with rounded edges fixed to a box-like middle section and a rear end that has an upper slanted surface. Based on a study by Thabet and Thabit [53], the Ahmed model is applied with a slant angle $\varphi$ equals to $40^{\circ}$, with $1044 \mathrm{~mm}$ of horizontal length $(L), 288 \mathrm{~mm}$ of vertical height $(H)$, and $389 \mathrm{~mm}$ of width $(W)$, as shown in Figure 2 . Based on inlet velocity, $v$ value $40 \mathrm{~m} / \mathrm{s}$, the value of drag coefficient forces $\left(C_{D}\right)$ and lift forces $\left(C_{L}\right)$ are 0.323 and 0.0368 respectively. The $k-\varepsilon$ turbulence model was utilised in this study due to its good convergence rate. The advantages of utilizing this model for the studies due to the simple geometry, geometric parameters, ease flow accessibility and drag data, and existing CFD experiences.

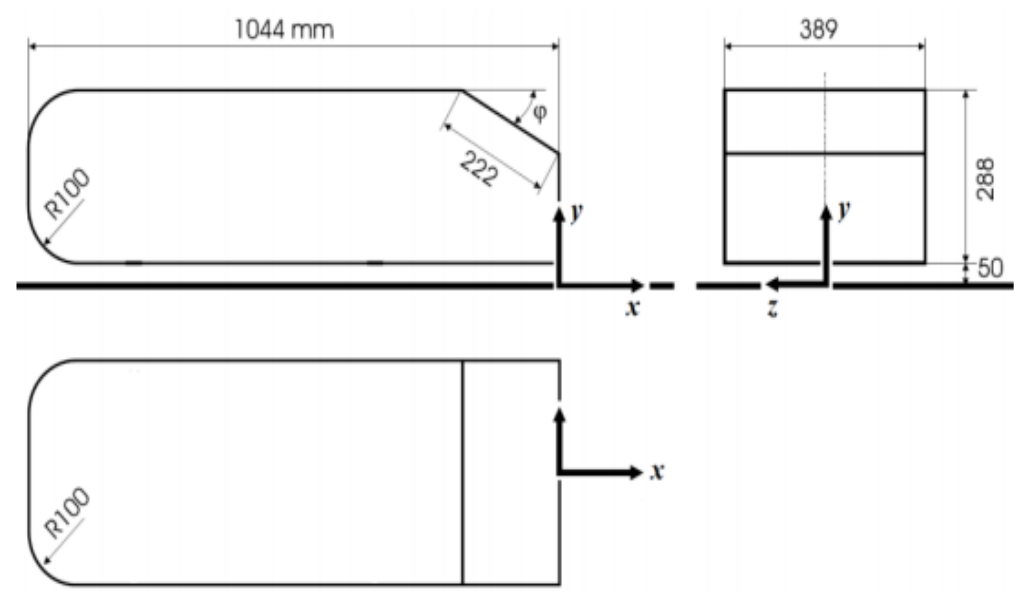

Fig. 2. The Ahmed model's dimensions employed by Thabet and Thabit [53]

Aerodynamics Studien Model (ASMO model) is another model that can be categorized as simple bodies. Daimler Benz research department has developed this geometry over a decade to examine low drag shapes and to provide a neutral body for measuring CFD codes [54,55]. The shape consists of a square-back rear, smooth surfaces, a boat tail, an underbody diffuser, and no pressure-induced boundary layer separation based on research employed by Le Good and Garry [24]. Han, on the other hand, applied the ASMO model in his study with the dimensions of length $(L)=810 \mathrm{~mm}$, height $(H)=$ $270 \mathrm{~mm}$ and width $(W)=290 \mathrm{~mm}$ [56]. Whilst an inlet velocity, $v$ utilised in this study is approximately $50 \mathrm{~m} / \mathrm{s}$ and numerical values obtained for the drag coefficient forces $\left(C_{D}\right)$ and lift forces $\left(C_{L}\right)$ are 0.165 and 0.125 respectively by using the Smagorinsky turbulence model. Many academics prefer to use simpler vehicle model such as the ASMO model as the shape of the model that can be easily meshed 
without the need of larger computer resources and the ability to achieve a good simulation effect as illustrated in Figure 3 [56].

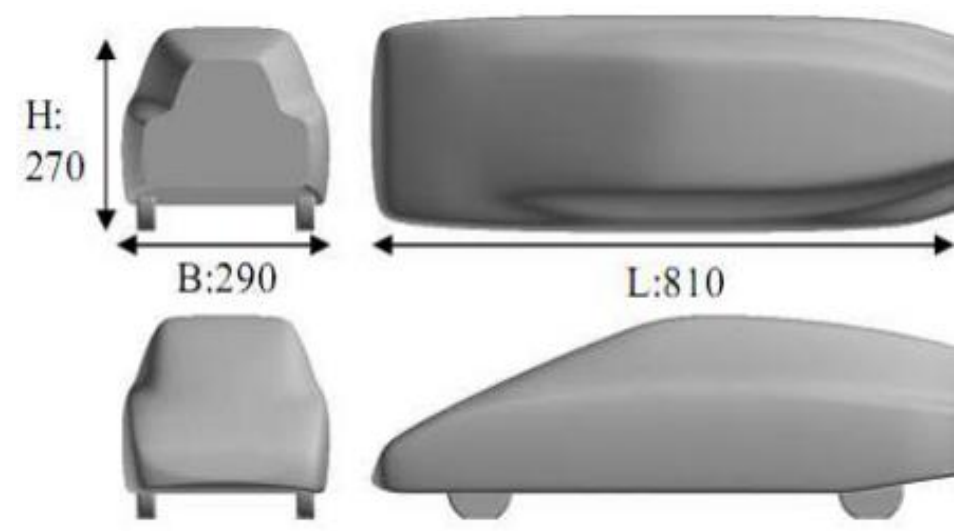

Fig. 3. The Aerodynamics Studien Model (ASMO model) utilised by Han et al., [56]

Davis model, on the other hand is a simple bluff body model utilised by researchers that involved fundamental flow characteristics. This model was established by Davis due to its ability to produce more accurate results that demonstrate measuring steady force and moments at fixed yaw angles by assuming quasi-steady flow [24]. Mansor et al., [57], employed the Davis model in his study with the dimensions of the length $(L)=625 \mathrm{~mm}$, height $(H)=160 \mathrm{~mm}$, width $(W)=225 \mathrm{~mm}$, and rear angle $=$ $20^{\circ}$, as shown in Figure 4 [57]. The inlet velocity, $v$ applied in this research is $40 \mathrm{~m} / \mathrm{s}$ with Reynolds number $1.7 \times 10^{6}$ based on the model length and numerical values obtained from the drag coefficient forces $\left(C_{D}\right)$ is 0.228 respectively. The $k-\omega$ turbulence model was chosen for CFD simulation as it can provide the closest agreement with pressure coefficient values against the $k-\varepsilon$ models.

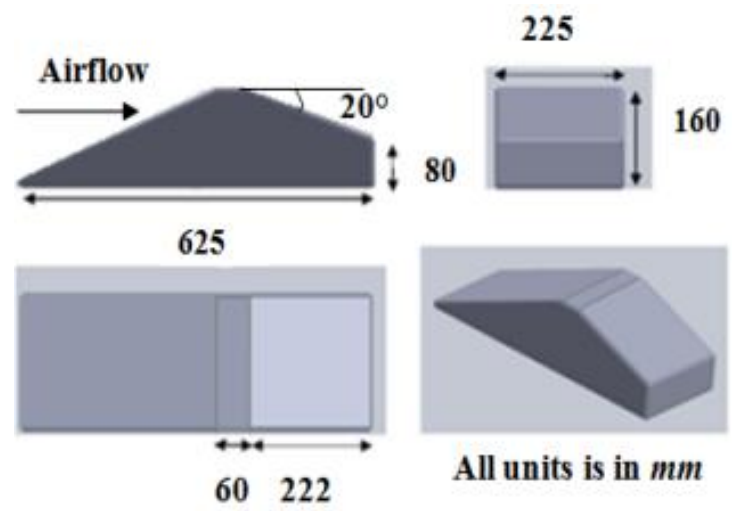

Fig. 4. The Davis model configurations used by Mansor et al., [57]

\subsubsection{Basic car shapes}

Referential geometries in this classification elucidate a more obvious form of vehicle shapes than in the simple bodies. These models have the proportions of production cars, but possess disentangled and streamlined surfaces. The basic car shapes consist of few external parts such as side mirrors and it is used for testing, validation, and research [58]. The example of basic car shapes illustrated in this review paper is classified into two, namely Motor Industry Research Association (MIRA) model and 
the TATA model. The MIRA Concept car is one of the most popular concept cars among other simplified car models that have been cited in 20 academic publications [24]. The original concept and idea of this model were carried out using manufacturing reference vehicles of Volkswagen 1600 and FIAT 124. As illustrated in Figure 5, Lai et al., [59], applied research geometry in the MIRA model build in CATIA with the length $(L)$, width $(W)$, and height $(H)$ of $520.625 \mathrm{~mm}, 203.125 \mathrm{~mm}$, and $177.625 \mathrm{~mm}$ respectively. In the study, the velocity inlet, $v$ is configured to $30 \mathrm{~m} / \mathrm{s}$, in which the outlet is identified as a pressure outlet, and the reference pressure is defined as atmospheric pressure. The numerical value achieved in this study for the drag coefficient $\left(C_{D}\right)$ is 0.329 . The $k-\varepsilon$ turbulence model is chosen for computational analysis due to its reasonable prediction of different flow types. Based from previous studies, this model exhibits simple surface geometry, systematic geometry scales, decreases computing power and cell capacity during simulation, and good optimism for numerical methods to predict flow around vehicle shapes [24].

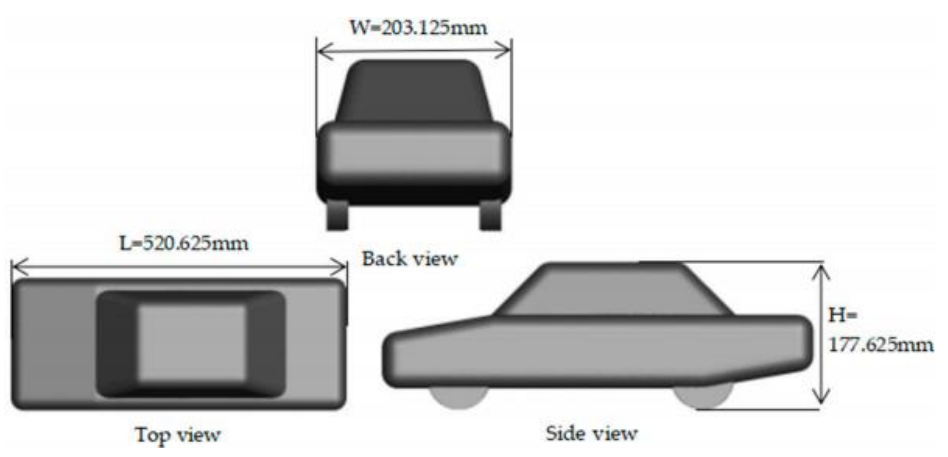

Fig. 5. Dimension of the MIRA model applied in Lai et al., [59]

TATA model is a fundamental car design from India that utilises a one-third scaled-down model and is considered as a simplified base model when it ignores external parts such as side mirrors and spoiler. This model can be divided into a few categories such as TATA Safari, TATA Nano, and TATA Indica. The findings of literature reviews revealed that Samy et al., [22] applied the TATA Safari model for the SUV segment with the length $(L)$ of $4655 \mathrm{~mm}$ and the width $(W)$ of $1855 \mathrm{~mm}$ [22]. The angle of the windshield is $32^{\circ}$ and it is located $100 \mathrm{~mm}$ from the centre of the front wheel as shown in Figure 6 . The drag coefficients $\left(C_{D}\right)$ and lift $\left(C_{L}\right)$ of this model are 0.620 and 0.099 respectively with the velocity inlet of $35 \mathrm{~m} / \mathrm{s}$ and 34 degrees atmospheric temperature. The $k-\varepsilon$ turbulence model is used in this study due to requirement of lesser computing resources as compared to other turbulence models. The findings revealed that the application of this model in the research can minimise computational time and yield good analysis.

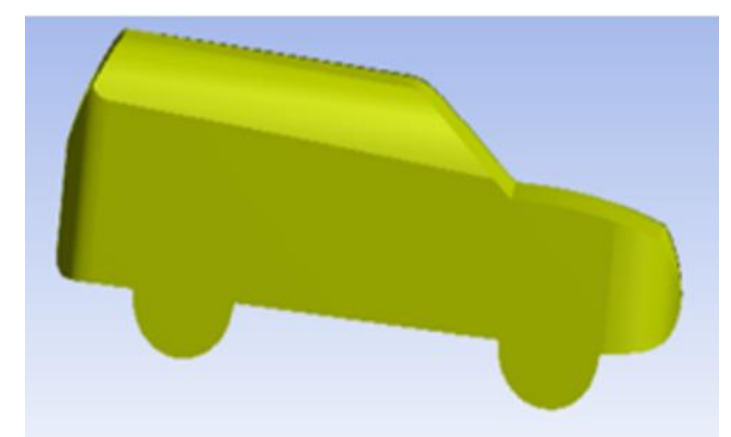

Fig. 6. TATA Safari model used by Samy et al., [22] 
Figure 7 illustrates research by Ansari [17] that utilised the TATA Indica model by importing sketches involved with blending 2D or 3D curves and rendering to produce realistic images. This model can be classified as an A-segment vehicle and compact car. The drag coefficient of $\left(C_{D}\right)$ the TATA Indica model is 0.841 with the velocity inlet of $19.44 \mathrm{~m} / \mathrm{s}$. The $k-\varepsilon$ turbulence model is employed to analyse the air flow field of the model due to its dissipation rate and short computational time.

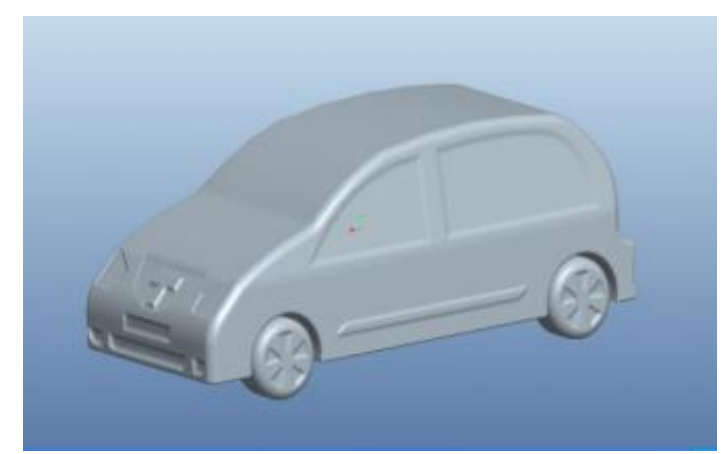

Fig. 7. TATA Indica model used by Ansari [17]

Datta et al., [60], utilised a generic car model without any exterior components to reduce complexity in the CFD simulation. Figure 8 elucidates specific dimensions of the base model car are about $4 \mathrm{~m}$ of base length $(L), 2 \mathrm{~m}$ of base width $(W)$, and $1.8 \mathrm{~m}$ of height $(H)$, but the design is maximised to 1:10 scale to improve the computational process. The inlet velocity utilised for this study is approximately $27.78 \mathrm{~m} / \mathrm{s}$ (measured along normal direction to the boundary) with the numerical value of drag coefficient $\left(C_{D}\right)$ and lift $\left(C_{L}\right)$ are 0.3385 and 0.2531 respectively. The $k-\varepsilon$ turbulence model is carried out to run computational analysis as it is robust with reasonable computational time and generally applied by automotive design engineers [60].

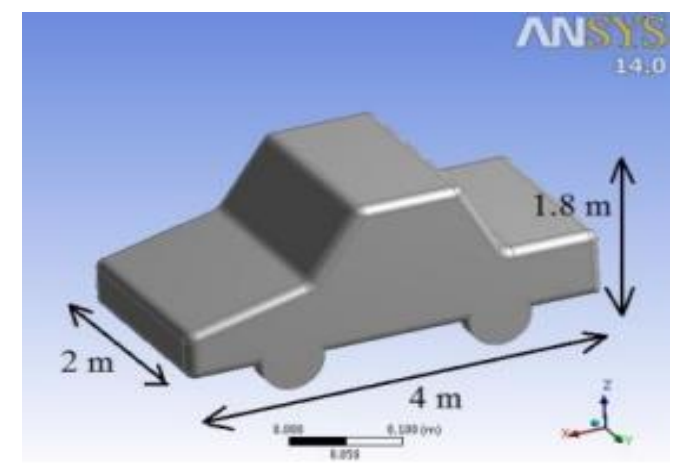

Fig. 8. Full-scale base model car utilised by Datta et al., [60]

\subsubsection{Production (series) cars}

The reference models in this category are detailed and exhibit a more complex form of actual vehicle shapes as compared to basic car shapes [61,62]. The differences between production (series) cars and basic car shapes are their external parts. Most production cars use actual ratio-scale, more precise geometry, include external parts such as side mirror and tires, and other related specific investigations as compared to the basic car shapes. Nevertheless, these models cannot produce smaller processing data and more systematic changes [24]. There are few examples of production 
(series) cars geometries applied in the previous studies namely KIA Pride, Swift Dzire, Volvo, Hybrid Electric Vehicle (HEV), and Range Rover models [23,58,63,64].

As annotated by Dias et al., [23], the Swift Dzire model is implemented by neglecting various complicated features such as exhaust and door handle to maximise the complexity of modelling during the computational process. This model can simplify the method of meshing, as a smaller number of surface and curves are used to construct a simpler topology although its side mirror remains. Figure 9 indicates the dimension of the vehicle is $3995 \mathrm{~mm}$ in length (L), $1555 \mathrm{~mm}$ in width $(W)$, and $1695 \mathrm{~mm}$ in height $(H)$ [23]. The inlet velocity applied for this research is $40 \mathrm{~m} / \mathrm{s}$ and the numerical value for drag coefficient $\left(C_{D}\right)$ is 0.375 . The $k-\omega$ turbulence model is chosen in this study to execute the CFD simulation as this model provides better prediction in regards with flow separation and also produce a good behaviour in adverse pressure gradients.

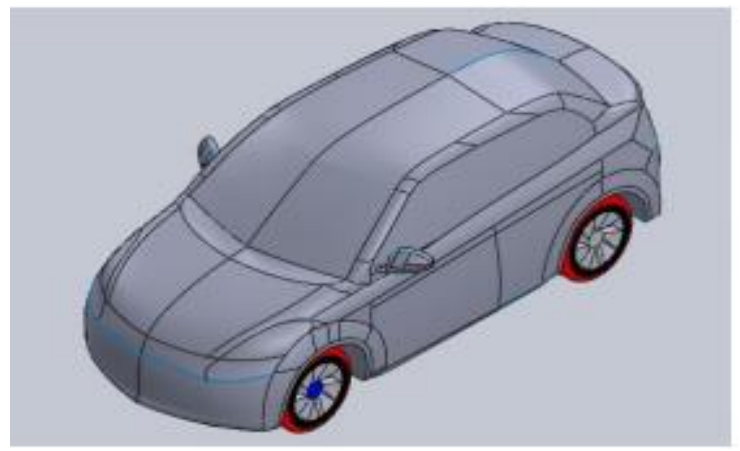

Fig. 9. The Swift Dzire model applied in computational analysis by Dias et al., [23]

Saleh and Ali [58] further performed the production (series) cars, KIA Pride model by ignoring the side mirrors, grilles, exhaust, tires without rotational motion and no solid contents as illustrated in Figure 10. The KIA Pride model has full-scale car dimensions for a small passenger car with a length $(L)$ of $3935 \mathrm{~mm}$, height $(H)$ of $1455 \mathrm{~mm}$, and width $(W)$ of $1605 \mathrm{~mm}$. The numerical value for the drag coefficient $\left(C_{D}\right)$ is 0.355 with the inlet velocity of $30 \mathrm{~m} / \mathrm{s}$. The $k-\varepsilon$ turbulence model is applied in this CFD simulation because it is feasible for less computational cost and free-shear layer flows with relatively small pressure gradients.

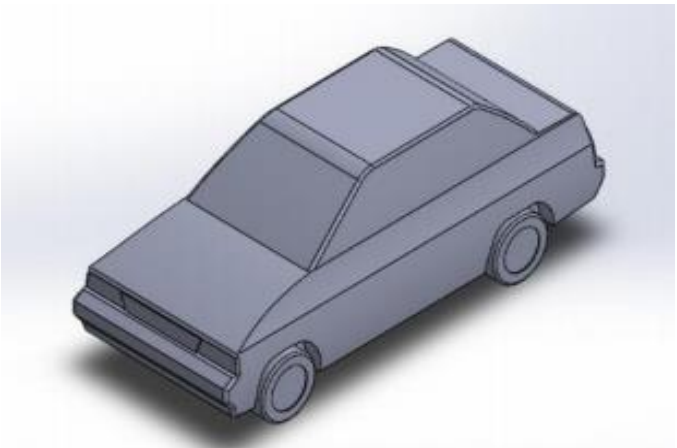

Fig. 10. The base model for the KIA pride used in simulation by Saleh and Ali [58]

Le Good et al., [65], annotated that the 'Resnick model' is created to investigate airflow and aerodynamic of vehicles. This concept adopts of autonomous driving technologies and it is suitable for high-riding coupe/SUV style with full-scale car dimensions of length $(L)=267 \mathrm{~mm}$, height $(H)=98$ $\mathrm{mm}$, and width $(W)=108 \mathrm{~mm}$, as shown in Figure 11 [65]. The numerical value for the coefficient 
drag $\left(C_{D}\right)$ is 0.27 with the inlet velocity of $40 \mathrm{~m} / \mathrm{s}$. The $k-\varepsilon$ turbulence model is utilised in computational analysis as it is easier to converge solution with reasonable predication and suitable in the case of free-shear layer flow conditions with small pressure gradients and wall-bounded [60].

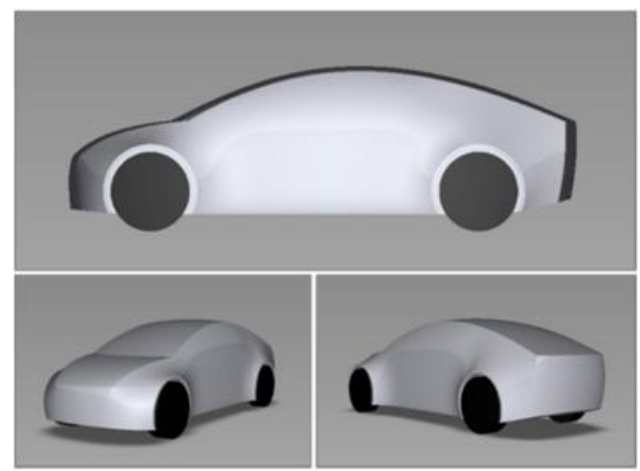

Fig. 11. Full-scale specification of the Resnick model applied in Le Good's et al., [65] simulation

Ramasamy et al., [64], utilized a Hybrid Electric Vehicle (HEV) model that is deconstructed and several exterior components are removed except tires. The purpose of ignoring these parts is to minimize the overall complexity design in the CFD simulation. The Hybrid Electric Vehicle (HEV) is the car design by Drayton and Coombs [66] that created using data measure in actual car model in the vehicle lab since 2003. Figure 12 illustrates specific dimensions of the HEV model car about $1360 \mathrm{~mm}$ of base height $(H), 1655 \mathrm{~mm}$ of base width $(W)$, and $4110 \mathrm{~mm}$ of length $(L)$ with $2380 \mathrm{~mm}$ of wheelbase. The inlet velocity applied for this research minimum and maximum values are $11.11 \mathrm{~m} / \mathrm{s}$ and $30.56 \mathrm{~m} / \mathrm{s}$. The numerical values of drag coefficient $\left(C_{D}\right)$ for the minimum and maximum values are 0.312 and 0.356 respectively. The $k-\varepsilon$ turbulence model is used to run the CFD simulation due to its accurate analysis of various fluid categories and as the most basic turbulence model that requiring only initial and boundary conditions [67].
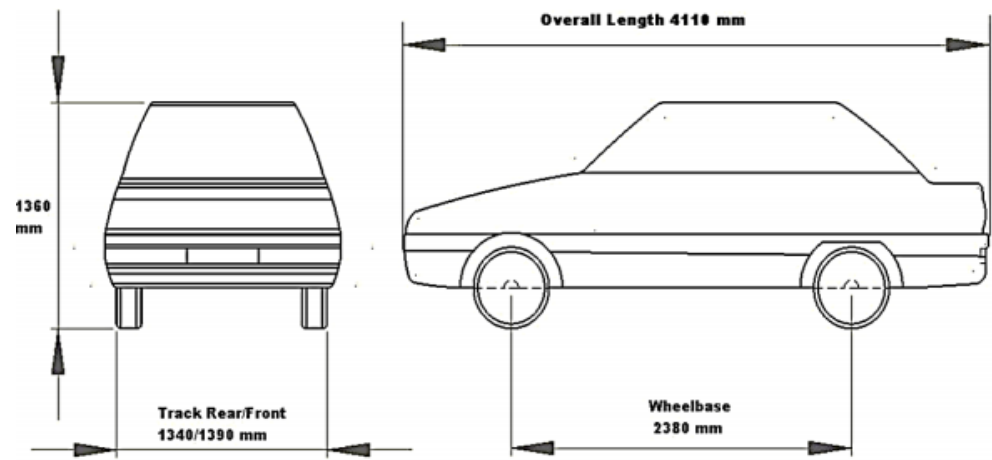

Fig. 12. The Hybrid Electric Vehicle (HEV) car model utilized in CFD simulation by Ramasamy et al., [64] 
Table 1

Summary of literature reviews based on various car geometries model

\begin{tabular}{|c|c|c|c|c|c|c|}
\hline $\begin{array}{l}\text { Car Model } \\
\text { Classification } \\
\text { (Type) }\end{array}$ & Author & $\begin{array}{l}\text { Inlet Velocity, } v \\
\text { / Reynolds } \\
\text { Number }\end{array}$ & $\begin{array}{l}\text { Aerodynamic } \\
\text { Loads }\end{array}$ & $\begin{array}{l}\text { Car } \\
\text { Dimensions } \\
(L \times H \times \\
W) \mathrm{mm}\end{array}$ & $\begin{array}{l}\text { Turbulence } \\
\text { Models }\end{array}$ & Software \\
\hline $\begin{array}{l}\text { Simple Bodies } \\
\text { (Ahmed Model) }\end{array}$ & $\begin{array}{l}\text { Thabet } \\
\text { and Thabit } \\
\text { [53] }\end{array}$ & $v=40 \mathrm{~m} / \mathrm{s}$ & $\begin{array}{l}-C_{D}=0.323 \\
-C_{L}=0.0368\end{array}$ & $\begin{array}{l}(1044 \mathrm{~mm} \times \\
288 \mathrm{~mm} \times \\
389 \mathrm{~mm})\end{array}$ & $\begin{array}{l}k-\varepsilon \\
\text { Turbulence } \\
\text { model }\end{array}$ & $\begin{array}{l}\text { Ansys } \\
\text { Fluent } \\
\text { Software }\end{array}$ \\
\hline $\begin{array}{l}\text { Simple Bodies } \\
\text { (ASMO Model) }\end{array}$ & $\begin{array}{l}\text { Han et al., } \\
{[56]}\end{array}$ & $v=50 \mathrm{~m} / \mathrm{s}$ & $\begin{array}{l}-C_{D}=0.165 \\
-C_{L}=0.125\end{array}$ & $\begin{array}{l}(810 \mathrm{~mm} \times \\
270 \mathrm{~mm} \times \\
290 \mathrm{~mm})\end{array}$ & $\begin{array}{l}\text { Smagorinsky } \\
\text { Turbulence } \\
\text { model }\end{array}$ & $\begin{array}{l}\text { XFlow } \\
\text { Software }\end{array}$ \\
\hline $\begin{array}{l}\text { Simple Bodies } \\
\text { (Davis Model) }\end{array}$ & $\begin{array}{l}\text { Mansor et } \\
\text { al., [57] }\end{array}$ & $\begin{array}{l}-v=40 \mathrm{~m} / \mathrm{s} \\
- \text { Reynolds } \\
\text { Number }=1.7 \times \\
10^{6}\end{array}$ & $-C_{D}=0.228$ & $\begin{array}{l}(625 \mathrm{~mm} \times \\
160 \mathrm{~mm} \times \\
225 \mathrm{~mm})\end{array}$ & $\begin{array}{l}k-\omega \\
\text { Turbulence } \\
\text { model }\end{array}$ & $\begin{array}{l}\text { Ansys } \\
\text { Fluent } \\
\text { Software }\end{array}$ \\
\hline $\begin{array}{l}\text { Basic Car } \\
\text { Shapes (MIRA } \\
\text { Model) }\end{array}$ & $\begin{array}{l}\text { Lai et al., } \\
{[59]}\end{array}$ & $v=30 \mathrm{~m} / \mathrm{s}$ & $-C_{D}=0.329$ & $\begin{array}{l}(520.625 \\
\mathrm{mm} \times \\
177.625 \mathrm{~mm} \\
\times 203.125 \\
\mathrm{~mm})\end{array}$ & $\begin{array}{l}k-\varepsilon \\
\text { Turbulence } \\
\text { model }\end{array}$ & $\begin{array}{l}\text { STAR } \\
\text { CCM+ } \\
\text { Software }\end{array}$ \\
\hline $\begin{array}{l}\text { Basic Car } \\
\text { Shapes (TATA } \\
\text { Safari Model) }\end{array}$ & $\begin{array}{l}\text { Samy et } \\
\text { al., [22] }\end{array}$ & $v=35 \mathrm{~m} / \mathrm{s}$ & $\begin{array}{l}-C_{D}=0.620 \\
-C_{L}=0.099\end{array}$ & $\begin{array}{l}(L=4655 \\
\mathrm{mm} \times W= \\
1855 \mathrm{~mm})\end{array}$ & $\begin{array}{l}k-\varepsilon \\
\text { Turbulence } \\
\text { model }\end{array}$ & $\begin{array}{l}\text { Ansys } \\
\text { Fluent } \\
\text { Software }\end{array}$ \\
\hline $\begin{array}{l}\text { Basic Car } \\
\text { Shapes (TATA } \\
\text { Indica Model) }\end{array}$ & Ansari [17] & $v=19.44 \mathrm{~m} / \mathrm{s}$ & $-C_{D}=0.841$ & $\begin{array}{l}\text { Imported 3D } \\
\text { sketches }\end{array}$ & $\begin{array}{l}k-\varepsilon \\
\text { Turbulence } \\
\text { model }\end{array}$ & $\begin{array}{l}\text { Ansys } \\
\text { Fluent } \\
\text { Software }\end{array}$ \\
\hline $\begin{array}{l}\text { Basic Car } \\
\text { Shapes (Base } \\
\text { Generic Model) }\end{array}$ & $\begin{array}{l}\text { Datta et } \\
\text { al., [60] }\end{array}$ & $v=27.78 \mathrm{~m} / \mathrm{s}$ & $\begin{array}{l}-C_{D}=0.3385 \\
-C_{L}=0.2531\end{array}$ & $\begin{array}{l}(4000 \mathrm{~mm} \times \\
1800 \mathrm{~mm} \times \\
2000 \mathrm{~mm})\end{array}$ & $\begin{array}{l}k-\varepsilon \\
\text { Turbulence } \\
\text { model }\end{array}$ & $\begin{array}{l}\text { Ansys } \\
\text { Fluent } \\
\text { Software }\end{array}$ \\
\hline $\begin{array}{l}\text { Production } \\
\text { (Series) Cars } \\
\text { (Swift Dzire } \\
\text { Model) }\end{array}$ & $\begin{array}{l}\text { Dias et al., } \\
{[23]}\end{array}$ & $v=40 \mathrm{~m} / \mathrm{s}$ & $-C_{D}=0.375$ & $\begin{array}{l}(3995 \mathrm{~mm} \times \\
1695 \mathrm{~mm} \times \\
1555 \mathrm{~mm})\end{array}$ & $\begin{array}{l}k-\omega \\
\text { Turbulence } \\
\text { model }\end{array}$ & $\begin{array}{l}\text { Ansys } \\
\text { Fluent } \\
\text { Software }\end{array}$ \\
\hline $\begin{array}{l}\text { Production } \\
\text { (Series) Cars } \\
\text { (KIA Pride } \\
\text { Model) }\end{array}$ & $\begin{array}{l}\text { Saleh and } \\
\text { Ali [58] }\end{array}$ & $v=30 \mathrm{~m} / \mathrm{s}$ & $-C_{D}=0.355$ & $\begin{array}{l}(3935 \mathrm{~mm} \times \\
1455 \mathrm{~mm} \times \\
1605 \mathrm{~mm})\end{array}$ & $\begin{array}{l}k-\varepsilon \\
\text { Turbulence } \\
\text { model }\end{array}$ & $\begin{array}{l}\text { Ansys } \\
\text { Fluent } \\
\text { Software }\end{array}$ \\
\hline $\begin{array}{l}\text { Production } \\
\text { (Series) Cars } \\
\text { (Resnick Model) }\end{array}$ & $\begin{array}{l}\text { Le Good et } \\
\text { al., [65] }\end{array}$ & $v=40 \mathrm{~m} / \mathrm{s}$ & $-C_{D}=0.270$ & $\begin{array}{l}(267 \mathrm{~mm} \times \\
98 \mathrm{~mm} \times \\
108 \mathrm{~mm})\end{array}$ & $\begin{array}{l}k-\varepsilon \\
\text { Turbulence } \\
\text { model }\end{array}$ & $\begin{array}{l}\text { Ansys } \\
\text { Fluent } \\
\text { Software }\end{array}$ \\
\hline $\begin{array}{l}\text { Production } \\
\text { (Series) Cars } \\
\text { (Hybrid Electric } \\
\text { Vehicle Model) }\end{array}$ & $\begin{array}{l}\text { Ramasamy } \\
\text { et al., [64] }\end{array}$ & $\begin{array}{l}v_{\text {Min }} \\
=11.11 \mathrm{~m} / \mathrm{s} \\
v_{\text {Max }} \\
=30.56 \mathrm{~m} / \mathrm{s}\end{array}$ & $\begin{array}{l}-C_{D_{\operatorname{Min}}}=0.312 \\
-C_{D_{\operatorname{Max}}}=0.356\end{array}$ & $\begin{array}{l}(4110 \mathrm{~mm} \times \\
1360 \mathrm{~mm} \times \\
1655 \mathrm{~mm})\end{array}$ & $\begin{array}{l}k-\varepsilon \\
\text { Turbulence } \\
\text { model }\end{array}$ & $\begin{array}{l}\text { CosmosFl } \\
\text { oWorks }^{\text {tm }} \\
\text { software. }\end{array}$ \\
\hline
\end{tabular}

\section{Outcomes}

Computational Fluid Dynamics (CFD) is the best method in dealing with complex equations and acquiring numerical solutions concerning complicated airflow equations as compared to experimental analysis. This is because the experimental analysis is often impracticable, requires a time-consuming process, expensive computational cost, and high tendency of human error [68]. Based on previous studies, the CFD simulation is mostly carried out using the Reynolds-Averaged Navier-Stokes Equation (RANS) due to its ability to generate a faster and cost-effective prediction of 
aerodynamics for automotive as compared to other approaches namely the Unsteady ReynoldsAveraged Navier-Stokes Equation (URANS) and the Large Eddy Simulation (LES).

On the other hand, several types of turbulence models are developed in the Reynolds-Averaged Navier-Stokes (RANS) approach. The greatest type of turbulence models used in this review paper is the $k-\varepsilon$ and the $k-\omega$ turbulence models. Launder and Spalding introduced the $k-\varepsilon$ turbulence model, which is the most commonly applied turbulence models by automotive designers due to its ease and simplicity in predicting accurate converge solution [60]. The $k-\omega$ turbulence model also can be utilised as it has the ability to predict flow separation greater than other RANS models and it can generate good analysis performance of the pressure gradients [57].

The outcomes of these review papers are scrutinised for 3 different types of car model geometry, namely the simple bodies, the basic car shapes, and the production (series) cars. The findings mainly focus on the drag coefficient of various car geometry model to provide better performance on an aerodynamic design by reducing the computational cost. The drag coefficient is identified by analysing velocity contours, pressure contours, turbulent kinetic energy, and others. For instance, different pressure contours for three different types of car model geometries are generated, as depicted in Figure 13, Figure 14, and Figure 15 to determine different separated flow regions and stagnation point in front of car models.

Based on a study by Thabet and Thabit [53], the highest value of static pressure (indicated as redcoloured region) can be sought in the centre of the approaching Ahmed body and the lowest value of static pressure (indicated as green-coloured region) can be identified at the separate flow region as shown in Figure 13 [53]. A significant increase of pressure contours in front of the model is due to the result of high-velocity acceleration, parallel with Bernoulli's principle when the high-pressure area corresponds with the low-speed area of the speed profile [69]. Research by Samy et al., [22] further indicates that the front model represents the high value of static pressure whilst pressure drop is experienced at the back and under the body of the vehicle which affects drag and lifts coefficients as exemplified in Figure 14 [22]. Major pressure reduction can be seen on the roof of the TATA Safari model due to the low-velocity acceleration as compared to the Ahmed model (the simple bodies).

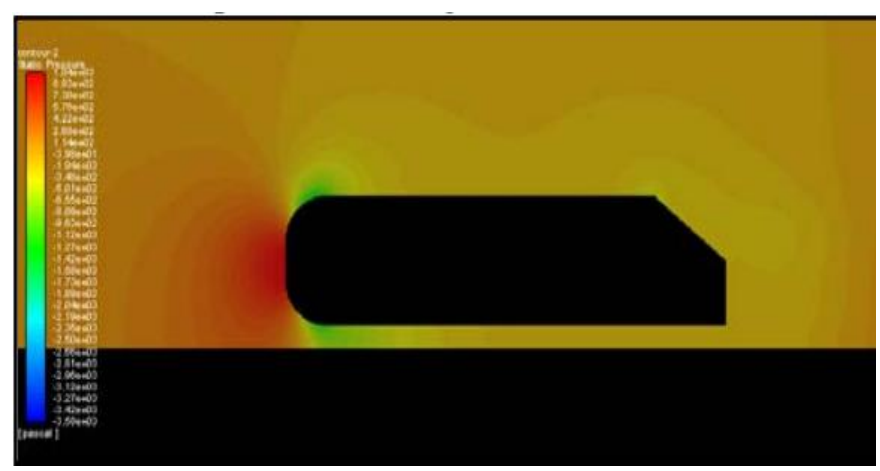

Fig. 13. Pressure contour that surrounds the Ahmed model (the simple body types) by Thabet and Thabit [53]

Figure 15 clearly shows stagnation points of pressure contour in front of the car model as air is almost stagnant in the mentioned regions as compared to the Ahmed model and the TATA safari model [23]. As a result of high-speed acceleration, the pressure profile in front of the model has increased significantly, corresponds to the low-velocity region. There are few large magnitudes of static pressures that exist on the upstream side, with little exaggeration of the pressure contour due to the existence of engine vents, grilles, and other open spaces that have been ignored during the 
modelling process for simplification. The results show that car model geometry for production (series) car types identified more various magnitudes of static pressure due to the complex form as actual vehicle shapes as compared to the simple bodies and the basic car shapes.

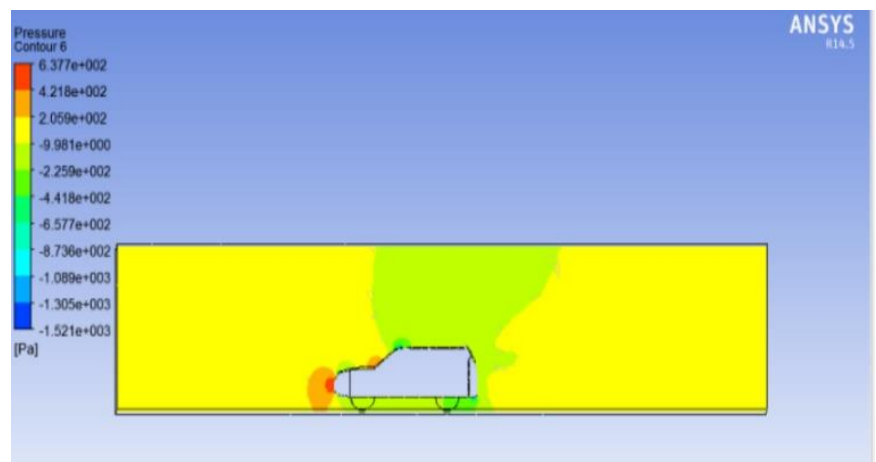

Fig. 14. Pressure contour surrounds the TATA Safari model (basic car shape types) by Samy et al., [22]

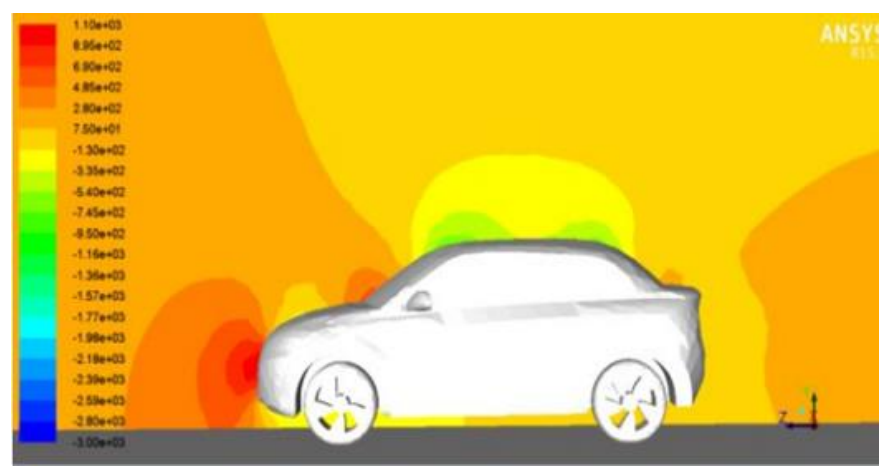

Fig. 15. Pressure contour surrounds the Swift Dzire model (production(series) car types) by Dias et al., [23]

Various shapes of the car model geometries such as the Ahmed model, the TATA Safari, and the Swift Dzire model can be implemented in aerodynamics forces and drag reduction studies. This is due to the model's applicability to run smoothly during simulation with certain conditions and parameters depending on the designs. There is a large volume of published literature that narrates about the simple bodies specifically in detail by previous researchers $[24,70]$.

The simple bodies have the greatest fundamental aerodynamic characteristics for a vehicle as compared to other types such as the basic car shapes and the production (series) cars. It also has been utilised to explore basic flow phenomena and structures, calibrate wind tunnels, and design or enhance research methods. In addition, it can also be implemented to provide data sources to evaluate the validation of experimental data and prepare test cases to verify CFD codes. Most of the simple bodies and the basic car shape geometries have been used for over 15 years, and many of these dimensions are based on the European family production vehicle of that era [24]. The simple bodies model remains to be widely used in fundamental research, especially in the study of unsteady effects.

As mention in past researchers, the advantages of this simple body reference model include encouraging researchers to reproduce prototypes easily, either physically or electronically such as in CAD model for CFD simulation. Moreover, the simplicity of the models enables them to quickly create contributing to repeatable results which give the researchers more confidence and enabling a good assessment of findings. The patterns in the impact of systematic shape adjustments on aerodynamic 
characteristics can be directly applied to the development of production cars even though the geometry is simple.

In terms of weakness, the results obtained from these simple bodies are limited and could not be transferable to production vehicle development that requires a more complex body surface. The simple models rarely provide features to simulate the cooling process and underbody flow due to its oversimplification in several scenarios such as in tests, which are commonly executed without any wheels [24]. Furthermore, the simple bodies can also eliminate the effects of the underbody flow for the vehicle especially when it is related to diffuser efficiency.

\section{Conclusions}

Aerodynamic design vehicles are significant in improving fuel efficiency during their life cycle, but due to the constraints of space optimization, not all technically feasible designs can be adopted. Hence, the current review paper proposes the CFD modelling and simulation strategy as a practical guide to simulate the external aerodynamics of different car models accurately within a period. Most researchers employ the Reynolds-Averaged Navier-Stokes (RANS) with the $k-\varepsilon$ and $k-\omega$ turbulence models due to their ability to predict surface flow visualizations, accurate pressure distributions, and low computational cost. The influence of various car model geometries on aerodynamic forces with different types of turbulence models are investigated and discussed by scrutinising various literature reviews from previous researchers.

The importance of review issues concerning the concept and design considerations of car models that influenced simulation effectiveness and aerodynamic performance especially in terms of drag forces are described in detail. The CFD simulation results have been thoroughly validated for three main types of car model geometries by analysing the flow separations in static pressure contours related to Bernoulli's concept. The difference in characteristics, results, and applications of the simple bodies, the basic car shapes, and the production (series) cars are observed. Based on the reviews, the most preferable car model geometries are the simple bodies as it is easy to mesh without any requirement of computer resources and capable to yield good simulation. The implementation of these simple body models has developed a wide understanding of basic aerodynamic flow characteristics concerning vehicles. Recently, these models have provided fundamental data and indepth information related to the non-steady effect of fluid flow and are utilised in an assessment to validate the CFD data. Thus, new models can only be developed if the dimensions of the current vehicle are required during an investigation and the models should be based on the existing geometries to enhance various shapes of models.

\section{Acknowledgements}

This research is financially supported by Universiti Tun Hussein Onn Malaysia under UTHM GPPS Grant (H725). The author would also like to thank the Faculty of Engineering Technology, Universiti Tun Hussein Onn Malaysia for providing feasible research facilities for this study. Communication of this research is made possible through monetary assistance by Universiti Tun Hussein Onn Malaysia and the UTHM Publisher's Office via Publication Fund E15216.

\section{References}

[1] Vančura, Jan. "Crosswind Sensitivity of Road Vehicles." In 20th International Conference Transport Means 2016 Proceedings Part I. Transport Means, p. 522-527. Kaunas University of Technology Press, 2016.

[2] Qi-Liang, Wang, Wu Zheng, Zhu Xian-Liang, Liu Li-Li, and Ying-Chao Zhang. "Analysis of Aerodynamic Performance of Tesla Model S by CFD." In 3rd Annual International Conference on Electronics, Electrical Engineering and Information Science (EEEIS 2017), pp. 16-21. Atlantis Press, 2017. https://doi.org/10.2991/eeeis-17.2017.3 
[3] Das, Rubel Chandra, and Mahmud Riyad. "CFD analysis of passenger vehicleat various angle of rear end spoiler." Procedia Engineering 194 (2017): 160-165. https://doi.org/10.1016/i.proeng.2017.08.130

[4] Srinivasarao, S., and V. M. Lakshamaih. "CFD Research on Car Body." International Journal of Recent Technology and Engineering (IJRTE) 8, no. 2S3 (2019): 1178-1180. https://doi.org/10.35940/ijrte.B1218.0782S319

[5] Sadikin, Azmahani, Nurul Akma Mohd Yunus, Saiful Anuar Abd Hamid, Salihatun Md Salleh, Mohd Nasrull Abdol Rahman, Shahruddin Mahzan, and Sallehuddin Shah Ayop. "A comparative study of turbulence models on aerodynamics characteristics of a NACA0012 airfoil." International Journal of Integrated Engineering 10, no. 1 (2018): 134-137. https://doi.org/10.30880/ijie.2018.10.01.019

[6] Ali, Imad Shukri, and Aws Akram Mahmood. "Improvement of aerodynamics characteristic of heavy trucks." In 3rd International Conference on Trends in Mechanical and Industrial Engineering, p. 246-255. 2013.

[7] De Leon, Adrian. "Improving Caravan Design by Modelling of Crosswind." PhD diss., University of Southern Queensland, 2016.

[8] Desai, Darshan M., and Imran Molvi. "Effect of various aerodynamic drag reduction methods on vehicle - a review." International Journal of Advance Engineering and Research Development 4, no. 6 (2017): 214-220. https://doi.org/10.21090/IJAERD.50716

[9] Tomar, Akhilesh Singh, Anuj Prajapati, Anuj Sharma, and Shubham Shrivastava. "CFD analysis on the aerodynamic effects of spoiler at different angle on car body." International Journal of Innovative Technology and Exploring Engineering (IJITEE) 8, no. 7 (2019): 2845-2848.

[10] Srinivas, V. L. "Shape optimization of a car body for drag reduction and to increase downforce." JNT University Anantapur (2016).

[11] Omar, Muhamad Hafiz Izzudin, Syabillah Sulaiman, and Muhammad Asri Azizul. "Analysis of Vehicle Ride and Handling Performance on Variable Vehicle Load and Speed Using Simulation Method." Progress in Engineering Application and Technology 2, no. 1 (2021): 667-682.

[12] Azmi, Mohammad Firdaus Mohammed, Mohammad Al Bukhari Marzuki, and Mohd Arzo Abu Bakar. "Vehicle aerodynamics analysis of a multipurpose vehicle using CFD." ARPN Journal of Engineering and Applied Sciences 12, no. 7 (2017): 2345-2350.

[13] Kulkarni, Shreenidhi R., Abhishek Kothari, Chetan Pavate, and Chinmay Dodmani. "Aerodynamic Simulation of A Truck To Reduce The Drag Force." International Journal of Engineering Research 4, no. 11 (2015): 613-617. https://doi.org/10.17950/ijer/v4s11/1108

[14] Džijan, I., A. Pašić, A. Buljac, and H. Kozmar. "Aerodynamic forces acting on a race car for various ground clearances and rake angles." Journal of Applied Fluid Mechanics 12, no. 2 (2019): $361-368$. https://doi.org/10.29252/jafm.12.02.28706

[15] Kshirsagar, Vipul, and Jayashri V. Chopade. "Aerodynamics of high performance vehicles." International Research Journal of Engineering and Technology (IRJET) 5, no. 3 (2018): 2182-2186.

[16] Maxemow, Shane. "That's a drag: The effects of drag forces." Undergraduate Journal of Mathematical Modeling: One+ Two 2, no. 1 (2009): 1-16. https://doi.org/10.5038/2326-3652.2.1.4

[17] Ansari, Abdul Razzaque. "CFD Analysis of Aerodynamic Design of Tata Indica Car." International Journal of Mechanical Engineering and Technology 8, no. 3 (2017): 344-355.

[18] Muyl, Frédérique, Laurent Dumas, and Vincent Herbert. "Hybrid method for aerodynamic shape optimization in automotive industry." Computers \& Fluids 33, no. 5-6 (2004): $849-858$. https://doi.org/10.1016/j.compfluid.2003.06.007

[19] Pathri, Bhargav Prajwal, and Piyush Gaur. "Behavior and Simulation of a Car Model Under Different Design Conditions using Low Speed Wind Tunnel." International Conference on Smart Technologies for Mechanical Engineering - (STME-2013) (2013).

[20] Vishwakarma, Yogendra Kumar, Mohit Raj Saxena, and P. K. Nagrajan. "Aerodynmic Improvement of Car Body." International Journal of Engineering Research \& Technology (IJERT) 3, no. 6 (2014): 1761-1763.

[21] Howell, Jeff, David Forbes, Martin Passmore, and Gary Page. "The effect of a sheared crosswind flow on car aerodynamics." SAE International Journal of Passenger Cars-Mechanical Systems 10, no. 1 (2017): 278-286. https://doi.org/10.4271/2017-01-1536

[22] Samy, G. S., S. Thirumalai Kumaran, M. Uthayakumar, M. Sivasubramanian, and Krishna Bhagavathi Sankar. "Numerical analysis of drag and lift coefficient of a Sport Utility Vehicle (SUV)." In Journal of Physics: Conference Series, vol. 1276, no. 1, p. 012013. IOP Publishing, 2019. https://doi.org/10.1088/1742-6596/1276/1/012013

[23] Dias, Gavin, Nisha R. Tiwari, Joju John Varghese, and Graham Koyeerath. "Aerodynamic Analysis of a Car for Reducing Drag Force." IOSR Journal of Mechanical and Civil Engineering (IOSR-JMCE) 13, no. 3 (2016): 114-118.

[24] Le Good, Geoffrey M., and Kevin P. Garry. "On the use of reference models in automotive aerodynamics." $S A E$ Technical Papers (2004). https://doi.org/10.4271/2004-01-1308 
[25] Abobaker, Mostafa, Abdulhafid M. Elfaghi, and Sogair Addeep. "Numerical Study of Wind-Tunnel Wall Effects on Lift and Drag Characteristics of NACA 0012 Airfoil." CFD Letters 12, no. 11 (2020): 72-82. https://doi.org/10.37934/cfdl.12.11.7282

[26] Bhaskaran, Rajesh, and Lance Collins. "Introduction to CFD basics." Cornell University-Sibley School of Mechanical and Aerospace Engineering (2002): 1-21.

[27] Wang, Bin, You-Lin Xu, Le-Dong Zhu, and Yong-Le Li. "Crosswind effect studies on road vehicle passing by bridge tower using computational fluid dynamics." Engineering Applications of Computational Fluid Mechanics 8, no. 3 (2014): 330-344. https://doi.org/10.1080/19942060.2014.11015519

[28] Versteeg, Henk Kaarle, and Weeratunge Malalasekera. An introduction to computational fluid dynamics: the finite volume method. Pearson Education, 2007.

[29] Soares, Renan Francisco. "Drag of road cars: cost-effective CFD setup, proposal of an aerodynamic concept and case studies." Universidade Federal de Uberlândia (2015).

[30] Salim, Salim Mohamed, and Kian Chuan Ong. "Performance of RANS, URANS and LES in the prediction of airflow and pollutant dispersion." In IAENG Transactions on Engineering Technologies, pp. 263-274. Springer, Dordrecht, 2013. https://doi.org/10.1007/978-94-007-4786-9 21

[31] Jehad, D. G., G. A. Hashim, A. K. Zarzoor, and C. S. Nor Azwadi. "Numerical study of turbulent flow over backwardfacing step with different turbulence models." Journal of Advanced Research Design 4, no. 1 (2015): 20-27.

[32] Karthik, T. S. D., and F. Durst. "Turbulence models and their applications." 10th Indo German Winter Academy (2011): 1-52.

[33] Baker, Chris, Federico Cheli, Alexander Orellano, Nicolas Paradot, Carsten Proppe, and Daniele Rocchi. "Cross-wind effects on road and rail vehicles." Vehicle System Dynamics 47, no. 8 (2009): 983-1022. https://doi.org/10.1080/00423110903078794

[34] Jain, Shubham, Nekkanti Sitaram, and Sriram Krishnaswamy. "Effect of Reynolds number on aerodynamics of airfoil with Gurney flap." International Journal of Rotating Machinery 2015 (2015). https://doi.org/10.1155/2015/628632

[35] Fiumara, Alessandro, Nicolas Gourdain, Vincent Chapin, Julien Senter, and Yannick Bury. "Numerical and experimental analysis of the flow around a two-element wingsail at Reynolds number $0.53 \times 106$." International Journal of Heat and Fluid Flow 62 (2016): 538-551. https://doi.org/10.1016/j.ijheatfluidflow.2016.08.005

[36] Biadgo, Asress Mulugeta, Aleksandar Simonović, Jelena Svorcan, and Slobodan Stupar. "Aerodynamic characteristics of high speed train under turbulent cross winds: A numerical investigation using unsteady-RANS method." FME Transactions 42, no. 1 (2014): 10-18. https://doi.org/10.5937/fmet1401010B

[37] Yusuf, Siti Nurul Akmal, Yutaka Asako, Nor Azwadi Che Sidik, Saiful Bahri Mohamed, and Wan Mohd Arif Aziz Japar. "A Short Review on RANS Turbulence Models." CFD Letters 12, no. 11 (2020): 83-96. https://doi.org/10.37934/cfdl.12.11.8396

[38] Ismail, Noor Iswadi, Mahamad Hisyam Mahamad Basri, Hazim Sharudin, Zurriati Mohd Ali, Ahmad Aliff Ahmad Shariffuddin, and Nik Muhammad Izwan Nik Mohd Kamel. "Investigations of Lift and Drag Performances on NeoPtero Micro UAV Models." Journal of Advanced Research in Fluid Mechanics and Thermal Sciences 84, no. 2 (2021): 50-62. https://doi.org/10.37934/arfmts.84.2.5062

[39] Altinisik, Armagan, Emre Kutukceken, and Habib Umur. "Experimental and numerical aerodynamic analysis of a passenger car: Influence of the blockage ratio on drag coefficient." Journal of Fluids Engineering 137, no. 8 (2015). https://doi.org/10.1115/1.4030183

[40] Cogan, Donavan. "The aerodynamic design and development of an urban concept vehicle through CFD analysis." PhD diss., Cape Peninsula University of Technology, 2016.

[41] Sosnowski, Marcin, Renata Gnatowska, Karolina Grabowska, Jarosław Krzywański, and Arkadiusz Jamrozik. "Numerical analysis of flow in building arrangement: Computational domain discretization." Applied Sciences 9, no. 5 (2019): 941. https://doi.org/10.3390/app9050941

[42] Çengel, Yunus, A., and John M. Cimbala. Fluid Mechanics: Fundamentals And Applications (First Edition). McGraw Hill Higher Education, 2006.

[43] Ishak, Izuan Amin, Mohamed Sukri Mat Ali, Fadhilah Mohd Sakri, Fathul Hakim Zulkifli, Nofrizalidris Darlis, Rahmah Mahmudin, Shaiful Fadzil Zainal Abidin, Muhamad Asri Azizul, Syabillah Sulaiman, Nor Afzanizam Samiran, and Amir Khalid. "Aerodynamic Characteristics Around a Generic Train Moving on Different Embankments under the Influence of Crosswind." Journal of Advanced Research in Fluid Mechanics and Thermal Sciences 61, no. 1 (2019): 106-128.

[44] Al-Saadi, Ahmed Ali Shakir. "Analysis of Novel Techniques of Drag Reduction and Stability Increase for Sport Utility Vehicles using Computational Fluid Dynamics." PhD diss., University of Leeds, 2019.

[45] Yakhot, V., S. A. Orszag, Siva Thangam, T. B. Gatski, and C. G. Speziale. "Development of turbulence models for shear flows by a double expansion technique." Physics of Fluids A: Fluid Dynamics 4, no. 7 (1992): 1510-1520. https://doi.org/10.1063/1.858424 
[46] Poroseva, Svetlana, and Gianluca laccarino. "Simulation of Separated Flows with the K-Epsilon Model." In APS Division of Fluid Dynamics Meeting Abstracts, vol. 54, pp. EE-007. 2001.

[47] Hassan, Saud. "Aerodynamics investigation of rear vehicle (Backlight angle)." PhD diss., Doctoral dissertation, Teesside University, 2014.

[48] Abd Halim, M. A., N. A. R. Nik Mohd, M. N. Mohd Nasir, and M. N. Dahalan. "The evaluation of k- $\varepsilon$ and k- $\omega$ turbulence models in modelling flows and performance of s-shaped diffuser." International Journal of Automotive and Mechanical Engineering 15, no. 2 (2018): 5161-5177. https://doi.org/10.15282/ijame.15.2.2018.2.0399

[49] Mohamed, Wan Mazlina Wan, Nirresh Prabu Ravindran, and Parvathy Rajendran. "A CFD Simulation on the Performance of Slotted Propeller Design for Various Airfoil Configurations." CFD Letters 13, no. 3 (2021): $43-57$. https://doi.org/10.37934/cfdl.13.3.4357

[50] Mazlan, Mohamad Zahid, Fazila Mohd Zawawi, Teeab Tahzib, Kamarulafizam Ismail, and Syahrullail Samion. "Performance Analysis of Highway Wind Turbine Enhanced with Wind Guide Vanes Using the Taguchi Method." CFD Letters 13, no. 3 (2021): 25-42. https://doi.org/10.37934/cfdl.13.3.2542

[51] Hughes, Thomas. "CFD Study of Flow over a Simplified Car Using Different Turbulence Models." PhD diss., University of Derby, 2018.

[52] Mukuvare, Arnold. "CFD Prediction of Separation Flow over a Simplified Car Model." PhD diss., The University of West of England Bristol, 2018.

[53] Thabet, Senan, and Thabit H. Thabit. "CFD simulation of the air flow around a car model (Ahmed body)." International Journal of Scientific and Research Publications 8, no. 7 (2018): 517-525. https://doi.org/10.29322/IJSRP.8.7.2018.p7979

[54] Tsubokura, Makoto, Toshio Kobayashi, Takuji Nakashima, Takahide Nouzawa, Takaki Nakamura, Huilai Zhang, Keiji Onishi, and Nobuyuki Oshima. "Computational visualization of unsteady flow around vehicles using high performance computing." Computers \& Fluids 38, no. $5 \quad$ (2009): 981-990. https://doi.org/10.1016/i.compfluid.2008.01.020

[55] Perzon, Sven, and Lars Davidson. "On transient modeling of the flow around vehicles using the Reynolds equation." In International Conference on Applied Computational Fluid Dynamics (ACFD) Beijing China, pp. 720-727. 2000.

[56] Han, Shan Ling, Zhi Yong Li, Jin Bin Li, and Ru Xing Yu. "Simulation Research on Aerodynamic Characteristics of Vehicle under Steady Crosswind Based on XFlow." In Applied Mechanics and Materials, vol. 494, pp. 138-141. Trans Tech Publications Ltd, 2014. https://doi.org/10.4028/www.scientific.net/AMM.494-495.138

[57] Mansor, S., N. A. R. Nik Mohd, and C. W. Chung. "Validation of CFD Modeling and Simulation of a Simplified Automotive Model." In Applied Mechanics and Materials, vol. 735, pp. 319-325. Trans Tech Publications Ltd, 2015. https://doi.org/10.4028/www.scientific.net/AMM.735.319

[58] Saleh, Z. M., and A. H. Ali. "Numerical Investigation of Drag Reduction Techniques in a Car Model." In IOP Conference Series: Materials Science and Engineering, vol. 671, no. 1, p. 012160. IOP Publishing, 2020. https://doi.org/10.1088/1757-899X/671/1/012160

[59] Lai, Chenguang, Hang Fu, Bo Hu, Zhiwei Ling, and Li Jiang. "Aerodynamic Drag Reduction and Optimization of MIRA Model Based on Plasma Actuator." In Actuators, vol. 9, no. 3, p. 64. Multidisciplinary Digital Publishing Institute, 2020. https://doi.org/10.3390/act9030064

[60] Datta, Basudev, Vaibhav Goel, Shivam Garg, and Inderpreet Singh. "Study of Various Passive Drag Reduction Techniques on External Vehicle Aerodynamics Performance: CFD Based Approach." International Research Journal of Engineering and Technology (IRJET) 6, no. 5 (2019): 1851-1871.

[61] Osorio, David Eduardo Aljure. "Aerodynamic analysis of complex geometries using CFD." PhD diss., Universitat Politècnica de Catalunya (UPC), 2017.

[62] Zhang, Chunhui, Charles Patrick Bounds, Lee Foster, and Mesbah Uddin. "Turbulence modeling effects on the CFD predictions of flow over a detailed full-scale sedan vehicle." Fluids 4, no. 3 (2019): 148. https://doi.org/10.3390/fluids4030148

[63] Anish, A., P. G. Suthen, and M. K. Viju. "Modelling and analysis of a car for reducing aerodynamic forces." International Journal of Engineering Trends and Technology 47, no. 1 (2017): 1-17. https://doi.org/10.14445/22315381/IJETT-V47P201

[64] Ramasamy, D., K. Mohanesan, K. Kadirgama, M. M. Noor, and M. M. Rahman. "Hybrid electric vehicle car body drag analysis using computational fluid dynamics." International Journal of Automotive and Mechanical Engineering 14 (2017): 4496-4507. https://doi.org/10.15282/ijame.14.3.2017.8.0355

[65] Le Good, Geoffrey, Max Resnick, Peter Boardman, and Brian Clough. "An Investigation of Aerodynamic Effects of Body Morphing for Passenger Cars in Close-Proximity." Fluids 6, no. 2 (2021): 64. https://doi.org/10.3390/fluids6020064

[66] Drayton, Spencer, and Mark Coombs. Proton (Haynes Service and Repair Manual Series). Haynes Publishing, 1997. 
[67] Mingliang, Wu, Mingzhe Rong, Fei Yang, Yi Wu, Jianzhong Zhu, and Chunping Niu. "A Comparative Study of k-epsilon Turbulence Model in DC Circuit Breaker." In 20th International Conference on Gas Discharges and their Applications, p. 47-50. 2014.

[68] Naiem, Mohd Azzeri Md, Ezzul Hanis Othman, Adi Maimun, Arifah Ali, Faizul Amri Adnan, Philip A. Wilson, and Mohd Zarhamdy Md. Zain. "Drag analysis of three rudder-shaped like bodies." Journal of Advanced Research in Fluid Mechanics and Thermal Sciences 78, no. 1 (2021): 11-22. https://doi.org/10.37934/arfmts.78.1.1122

[69] Qin, Ruqiong, and Chunyi Duan. "The principle and applications of Bernoulli equation." In Journal of Physics: Conference Series, vol. 916, no. 1, p. 012038. IOP Publishing, 2017. https://doi.org/10.1088/17426596/916/1/012038

[70] Chaware, Swapnil D., and Yuvraj P. Pawar. "Study of Cross Wind for Heavy Vehicles and Analysis over Ahmad body." International Journal of Engineering Development and Research (IJEDR) 5, no. 4 (2017): 869-874. 